\title{
PREPARATION OF ANION-EXCHANGE CELLULOSE FOR THE REMOVAL OF CHROMATE
}

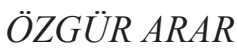

Ege University Faculty of Science, Department of Chemistry, Izmir 35040, Turkey

\section{ABSTRACT}

The quaternary ammonium group containing cellulose was prepared by the one-pot method and applied for the removal of chromate $\left(\mathrm{CrO}_{4}{ }^{2-}\right)$ ions from aqueous solution. The prepared sorbent was characterized by using elemental analyzer and Fourier transform infrared (FTIR) spectroscopy. Its ion exchange behavior toward $\mathrm{CrO}_{4}{ }^{2-}$ ions was investigated as a function of sorbent dose and initial solution $\mathrm{pH}$. The kinetic and sorption equilibrium experiments were also carried out in a batch system. Equilibrium data were best fitted with the Langmuir model and the maximum ion exchange capacity of the sorbent was found as $3.8 \mathrm{mg}$ of CrO ${ }_{4}^{2-} / \mathrm{g}^{2}$ sorbent. Moreover, the removal of $\mathrm{CrO}_{4}{ }^{2-}$ is achieved within 5 minutes. Furthermore, the calculated thermodynamic parameters disclosed that the ion exchange reaction is feasible, spontaneous and exothermic. In addition, the $\mathrm{CrO}_{4}{ }^{2-}$ ions can be desorbed from the sorbent by $1.0 \mathrm{M} \mathrm{HCl}$ solution with $95 \%$ regeneration efficiency.

Keywords: Anion exchange, cellulose, chromate, quaternized cellulose, water treatment

\section{INTRODUCTION}

Chromium is primarily present in trivalent and hexavalent states as chromate $\left(\mathrm{CrO}_{4}{ }^{2-}\right)$ and dichromate $\left(\mathrm{Cr}_{2} \mathrm{O}_{7}^{2-}\right)$ in aqueous media [1,2]. Chromic acid is used in the plating and anodizing operations in the surface finishing industry and chromium salts has been used widely in metal plating, leather tanning, dye, printing inks, photography and wood preservatives [3-6].

The two common oxidation states, i.e. $\mathrm{Cr}(\mathrm{III})$ and $\mathrm{Cr}(\mathrm{VI})$, are drastically different in charge, physicochemical properties as well as chemical and biochemical reactivity. The distribution of compounds containing in trivalent and hexavalent states depends on the redox potential, $\mathrm{pH}$ of the media, the existence of substance which is oxidizer or reducer, the formation of chromium(III) insoluble salts or its complexes, and the total chromium concentration. $\mathrm{Cr}$ (III) is a trace essential element for the proper functioning of living organisms. It is responsible for the control of glucose and lipid metabolism in mammals. On the other hand, The $\mathrm{Cr}(\mathrm{VI})$ is acutely toxic, carcinogenic, it is also highly soluble and mobile in an aqueous environment. The World Health Organization has recommended that the maximum allowable concentration of $\mathrm{Cr}(\mathrm{VI})$ in drinking water be $0.05 \mathrm{mg} / \mathrm{L}[2,7-9]$. In order to reduce the $\mathrm{Cr}(\mathrm{VI})$ concentration to permissible level; adsorption, ion exchange, membrane processes, and polymeric sorbents were used $[5,10-14]$. It should be noted that such methods can be ineffective or too expensive to treat wastes having metal ions in concentrations of $100 \mathrm{mg} / \mathrm{L}$ or below. Hence, there is a constant need to search for an optimal technology while considering its cost, materials employed and its efficiency [15].

In respect of bio-sorption, development of a specific sorbent that is environmentally friendly, safe with high capacity and low cost is still a challenging task and biopolymers are used for this purpose $[16,17]$. Biopolymers are derived from plant, animal or microbial biomass that may be polysaccharides, lipopolysaccharides, glycolipids, proteins, or polyhydroxy alkanoates and are well amenable to environmental applications [18]. Cellulose is the most abundant organic raw material and finds applications in areas as diverse as composite materials, textiles, drug delivery systems, and personal care products [19]. Cellulosic materials have several advantages such as; biodegradable and $\mathrm{CO}_{2}$ neutral; an abundant resource and has Low cost. Besides these advantages, it has High specific strength and modulus, high sound damping performance due to the hollow structure of fibers, low density and a relatively reactive surface, which can be used for surface modification [20]. The application, modification, advantages, and disadvantages of cellulose are already reviewed elsewhere [1922].

In this work, quaternary ammonium group-containing cellulose was prepared via one-pot modification process and it was applied for the removal of $\mathrm{CrO}_{4}{ }^{2-}$ ion from aqueous solution. Moreover, the Elemental analyzer and Fourier transform infrared (FT-IR) spectroscopy were made use of to characterize prepared anion exchange cellulose. Furthermore, the effect of sorbent dose, initial solution $\mathrm{pH}$, initial $\mathrm{CrO}_{4}{ }^{2-}$ concentration on ion exchange performance of modified cellulose were tested. In addition to this, sorption isotherms, kinetic performance and thermodynamic parameters for the $\mathrm{CrO}_{4}^{2-}$ were investigated. Finally, the regeneration of $\mathrm{CrO}_{4}{ }^{2-}-$ loaded cellulose was evaluated by batch experiments.

\section{EXPERIMENTAL}

\subsection{Reagents}

The cellulose raw material was obtained from Denkim Kimya A.Ş. (Denizli, Turkey) and used without modification or any treatment. Glycidyltrimethylammonium chloride (GTMAC, $80 \%$ aqueous solution, TCI) and $\mathrm{NaOH}$ (Merck) was used for the modification of cellulose. The $\mathrm{K}_{2} \mathrm{CrO}_{4}$ (Merck) was used for the preparation of $\mathrm{CrO}_{4}{ }^{2-}$ solutions. $\mathrm{HCl}$ (Merck) and $\mathrm{NaOH}$ (Merck) solutions were used for the $\mathrm{pH}$ adjustment.

\subsection{Preparation of anion exchange cellulose}

Cellulose was modified as explained in [23]. Briefly, $20 \mathrm{~g} \mathrm{NaOH}$ dissolved in $250 \mathrm{~g}$ pure water and when the temperature of this solution reached $65^{\circ} \mathrm{C}$ then, $30 \mathrm{~g}$ cellulose was added to $\mathrm{NaOH}$ solution. After ten minutes of adding cellulose, $25 \mathrm{~g}$ glycidyltrimethylammonium chloride solution $(80 \%$ aqueous solution) was added to the suspension with stirring and the reaction was carried out at $65^{\circ} \mathrm{C}$ for 270 minutes. Subsequently, $2 \mathrm{M} \mathrm{HCl}$ solution was added to the reaction medium to stop the modification reaction. The reaction mixture was filtered, washed with pure water and then dried in an oven at $50{ }^{\circ} \mathrm{C}$. Dried anion exchange cellulose was milled and used in the experiments.

\subsection{Characterization of ion-exchange cellulose}

The functional groups of prepared cellulose were characterized by the Fourier transform infrared spectroscopy (FT-IR, PerkinElmer one-B, coupled with an ATR accessory) in the range of $600-4000 \mathrm{~cm}^{-1}$. Leco CHNS-932 elemental analyzer was used for the compositional analysis of ion-exchange cellulose.

\subsection{Experimental procedure for the removal of $\mathrm{CrO}_{4}{ }^{2-}$}

In order to find obtain the highest removal rate of $\mathrm{CrO}_{4}^{2-}$, different parameters were tested. The experimental conditions of batch sorption tests were summed up in Table 1. Standard diphenylcarbazide method [24] was utilized for the spectrophotometric determination of $\mathrm{CrO}_{4}^{2-}$ in aqueous samples by using PG $\mathrm{T} 80+$ spectrophotometer.

Table 1. Experimental parameters for removal of $\mathrm{CrO}_{4}{ }^{2-}$

\begin{tabular}{|c|c|c|c|c|c|}
\hline $\begin{array}{c}\text { Investigated } \\
\text { parameter }\end{array}$ & $\begin{array}{c}\mathbf{C r O}^{2^{2}} \\
\mathbf{c o n c e n t r a t i o n} \\
(\mathbf{m g / L})\end{array}$ & $\begin{array}{c}\text { Amount of } \\
\text { sorbent (g) }\end{array}$ & $\begin{array}{c}\text { Volume of } \\
\text { solution (mL) }\end{array}$ & $\begin{array}{c}\mathbf{p H} \text { of } \\
\text { solution }\end{array}$ & $\begin{array}{c}\text { Temperature } \\
\left({ }^{\circ} \mathbf{C}\right)\end{array}$ \\
\hline Sorbent dose & 5 & $0.02-0.3$ & 25 & 7 & 25 \\
\hline Initial solution pH & 5 & 0.2 & 25 & $2-10$ & 25 \\
\hline Equilibrium study & $25-400$ & 0.2 & 25 & 10 & 25 \\
\hline Temperature effect & 25 & 0.2 & 25 & 10 & 30,40 and 50 \\
\hline Kinetic study & 5 & 8 & 1000 & 10 & 25 \\
\hline
\end{tabular}

email:ozgur.arar@ege.edu.tr 
The percent removal ( $\mathrm{R} \%$ ) of $\mathrm{CrO}_{4}{ }^{2-}$ was calculated with Eqn. 1 and capacity of sorbent (q as $\mathrm{mg}-\mathrm{CrO}_{4}{ }^{2-} / \mathrm{g}$-sorbent) was calculated with Eqn.2.

$$
\begin{aligned}
& R(\%)=\frac{C_{0}-C_{e}}{C_{0}} x 100 \\
& q=\frac{\left(C_{0}-C_{e}\right) x V}{m} \ldots \ldots . . .
\end{aligned}
$$

In these equations, $\mathrm{C}_{0}$ is the initial concentration of $\mathrm{CrO}_{4}{ }^{2-}(\mathrm{mg} / \mathrm{L}), \mathrm{C}_{\mathrm{e}}$ is the concentration of $\mathrm{CrO}_{4}{ }^{2-}$ in the solution after sorption experiment $(\mathrm{mg} / \mathrm{L})$. V is the volume of solution $(\mathrm{L})$ and $\mathrm{m}$ is the mass of the quaternized cellulose $(\mathrm{g})$.

\section{RESULTS AND DISCUSSIONS}

\subsection{Characterization of the anion exchange cellulose}

The FTIR-ATR spectra of raw and quaternized cellulose is shown in Figure 1. Infrared spectra of raw and quaternized cellulose show many similarities. The peak at $3339 \mathrm{~cm}^{-1}$ is due to stretching vibration frequencies of the -OH groups. The bands at 2898 and $1420 \mathrm{~cm}^{-1}$ probably be attributed to deformation vibrations of $\mathrm{CH}_{2}$ groups. The band at $1315 \mathrm{~cm}^{-1}$ is the deformation vibrations of $\mathrm{OH}-$ groups. The peaks at 1159,1051 , and $1028 \mathrm{~cm}^{-1}$ are involved $\mathrm{C}-\mathrm{O}$ stretching of $\mathrm{COH} / \mathrm{C}-\mathrm{O}-\mathrm{C}$ bonds. The band at $897 \mathrm{~cm}^{-1}$ in the spectrum is attributed to stretching vibrations of the ring/semi-circle cellulose [25-27]. In addition to FTIR analysis, the elemental analysis was also used to confirm the presence of nitrogen $(\mathrm{N})$ in the quaternized cellulose. The composition of the raw and modified cellulose is shown in Table 2 .

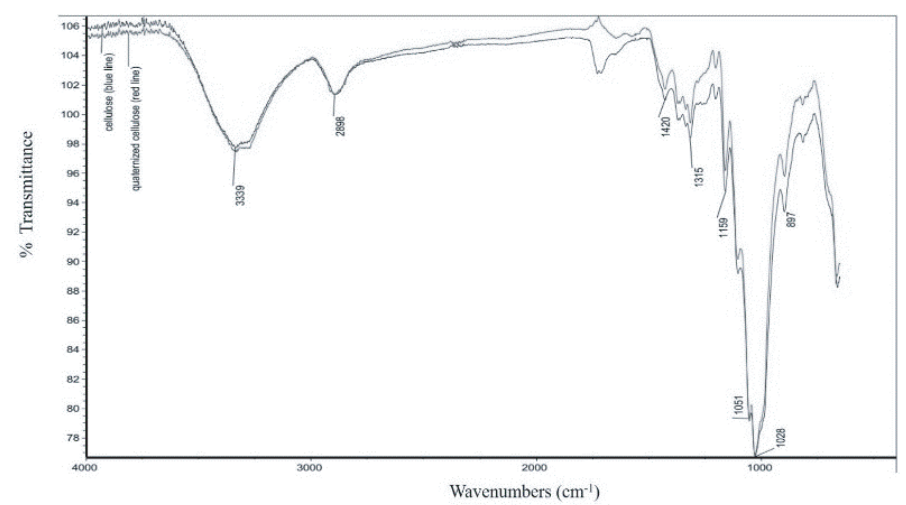

Figure 1. FTIR spectrum of raw and quaternized cellulose

Table 2. Elemental composition of the raw and quaternized cellulose

\begin{tabular}{|l|c|c|c|}
\hline Material & $\mathbf{C} \%$ & H \% & N \% \\
\hline Raw cellulose & 41.89 & 6.21 & - \\
\hline Quaternized cellulose & 42.92 & 6.49 & 0.23 \\
\hline
\end{tabular}

As can be seen from Table 2, raw cellulose does not contain Nitrogen element. The amount of nitrogen in the quaternized cellulose was $0.23 \%$. Moreover, after attaching the quarter groups to the cellulose, the percentage $\mathrm{C}$ and $\mathrm{H}$ in the sorbent increased. The quaternary ammonium groups also contain $\mathrm{CH}_{3}$ groups and this leads to increment on $\mathrm{C}$ and $\mathrm{H}$ percentage.

\subsection{Effect of sorbent dose on $\mathrm{CrO}_{4}{ }^{2-}$ removal.}

The percent removal of $\mathrm{CrO}_{4}{ }^{2-}$ versus sorbent dose is shown in Figure 2. The curve indicates that removal of $\mathrm{CrO}_{4}{ }^{2-}$ increases with increase in the sorbent dose due to the greater availability of the sorption sites [28]. The optimal amount of sorbent for $\mathrm{CrO}_{4}{ }^{2-}$ removal was $0.2 \mathrm{~g}$ sorbent $/ 25 \mathrm{~mL}$ solution and such sorbent dose used in subsequent experiments. Prepared sorbent removed $99 \%$ of $\mathrm{CrO}_{4}{ }^{2-}$ from solution.

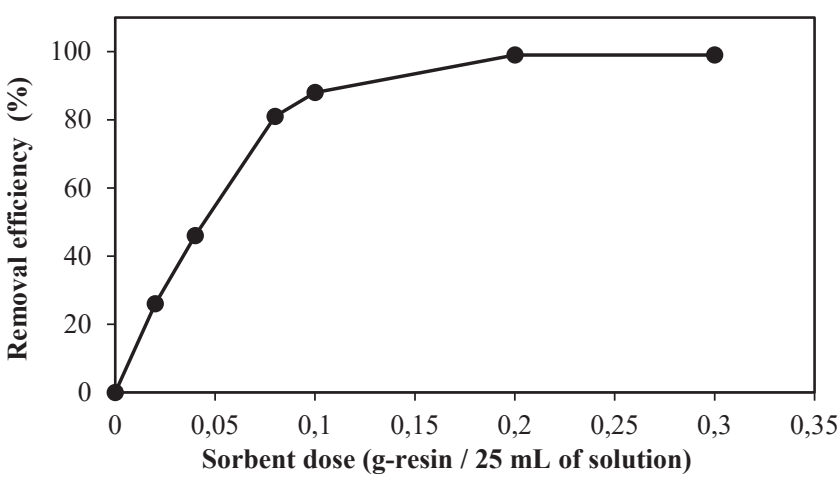

Figure 2. Removal of $\mathrm{CrO}_{4}{ }^{2-}$ versus sorbent dose.

\subsection{Effect of initial solution $\mathrm{pH}$}

The uptake of $\mathrm{CrO}_{4}^{2-}$ by quaternized cellulose at different $\mathrm{pH}$ is shown in Figure 3. When the $\mathrm{pH}$ of the solution was adjusted to 2 , only $36 \%$ of $\mathrm{CrO}_{4}^{2-}$ removed from the solution. Increment on solution $\mathrm{pH}$ leads to enhancement on $\mathrm{CrO}_{4}{ }^{2-}$ removal. It was reached maximum at pH 8 and 10 (99\% removal).

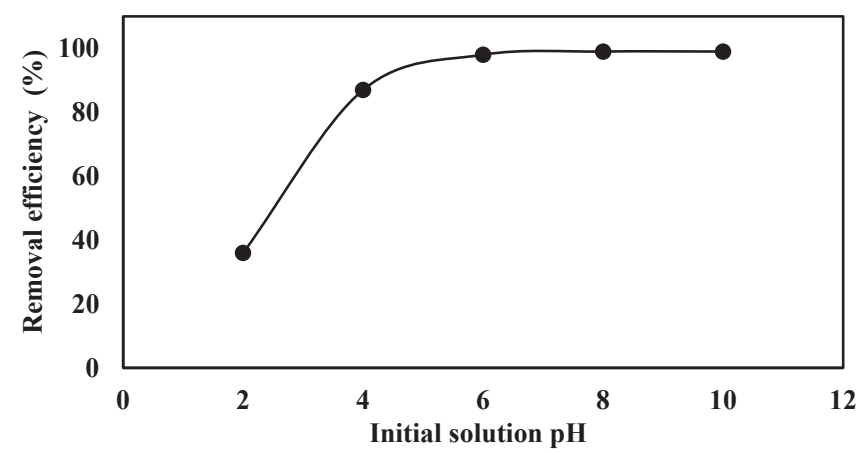

Figure 3. Effect of initial solution $\mathrm{pH}$ on the uptake of chromate

Such results can be explained as follows. The ion exchange reaction between $\mathrm{CrO}_{4}^{2-}$ and quaternized cellulose is shown in Eqn. 3

2 cellulose $-\left[\mathrm{N}\left(\mathrm{CH}_{3}\right)_{3}\right]^{+} \mathrm{Cl}^{-}+\mathrm{CrO}_{4}{ }^{2-} \leftrightarrows\left(\text { cellulose }-\left[\mathrm{N}\left(\mathrm{CH}_{3}\right)_{3}\right]^{+}\right)_{2} \mathrm{CrO}_{4}{ }^{2-}+2 \mathrm{Cl} \mathrm{l}^{-}$.

In order to adjust the $\mathrm{pH}$ of the solution to 2 and 3 , the $\mathrm{HCl}$ solution was added to the solution. When the $\mathrm{HCl}$ solution was added the $\mathrm{Cl}^{-}$concentration in the solution increased and according to Le Chatelier's principle reaction shifted to the left-hand side thus percent removal of $\mathrm{CrO}_{4}{ }^{2-}$ decreased.

As can be seen from Figure 3 the optimum $\mathrm{pH}$ values found as $\mathrm{pH} \geq 6$.

\subsection{Kinetic study}

Another set of experiments was also performed in order to clarify the kinetics of $\mathrm{CrO}_{4}^{2-}$ removal by quaternized cellulose and obtained results are depicted in Figure 4.

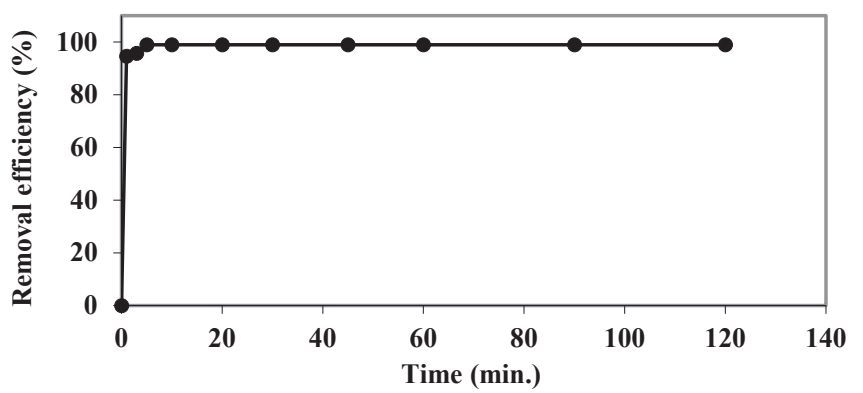

Figure 4. Change of percent removal of $\mathrm{CrO}_{4}{ }^{2-}$ as a function of time 
It is clear from Figure 4 that, kinetic of the sorbent is quite fast and $99 \%$ of $\mathrm{CrO}_{4}{ }^{2-}$ removed in 5 minutes.

\subsection{Sorption isotherm}

Isotherm studies give information about the capacity of the prepared sorbent. The sorption isotherm for $\mathrm{CrO}_{4}^{2-}$ is represented in Figure 5 .

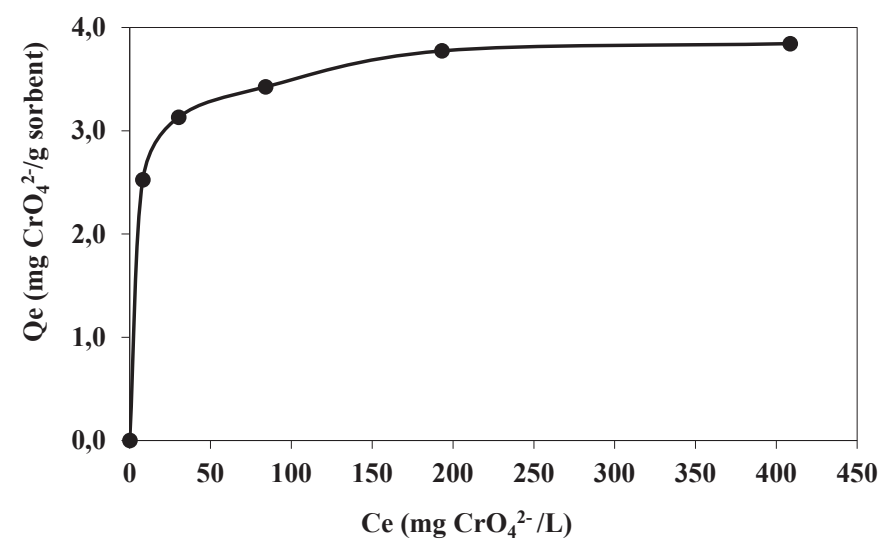

Figure 5. Sorption isotherm for $\mathrm{CrO}_{4}^{2-}$

Figure 5 represents that, when the initial $\mathrm{CrO}_{4}{ }^{2-}$ concentration in the solution was increased, the capacity of sorbent increased and then reached to its maximum sorption capacity. In order to obtain the theoretical sorption capacity, experimental results were fitted to the two most common isotherm models, i.e., the Langmuir and Freundlich models. The Langmuir equation is valid for monolayer sorption onto a surface is given as follows $[29,30]$

$$
\frac{C_{e}}{Q_{e}}=\frac{1}{b Q_{0}}+\frac{C_{e}}{Q_{0}}
$$

Ce is equilibrium concentration $(\mathrm{mg} / \mathrm{L})$, Qe is the amount sorbed ion under equilibrium $(\mathrm{mg} / \mathrm{g}), \mathrm{Q}_{0}$ is the theoretical maximum sorption capacity, and $\mathrm{b}$ $(\mathrm{L} / \mathrm{mg})$ is a Langmuir constant, which indicates the affinity of the $\mathrm{CrO}_{4}{ }^{2-}$ toward the quaternized cellulose.

The Freundlich equation, indicative of surface heterogeneity of the adsorbent, is given as follows

$$
\log Q_{e}=\log K_{F}+\frac{1}{n} \log C_{e}
$$

$1 / \mathrm{n}$ and $\mathrm{K}_{\mathrm{F}}$ are Freundlich constants, related to sorption capacity and sorption intensity (heterogeneity factor), respectively, Qe is the amount of $\mathrm{CrO}_{4}{ }^{2-}$ sorbed per unit weight of the sorbent (mg/g-sorbent), and $\mathrm{Ce}$ is the equilibrium concentration of sorbate in solution $(\mathrm{mg} / \mathrm{L})$. The obtained and calculated parameters were summarized in Table 3.

It can be seen that the correlation coefficient $\left(\mathrm{R}^{2}\right)$ values of Langmuir model is significantly higher than that of Freundlich model for $\mathrm{CrO}_{4}{ }^{2-}$ removal. According to the Langmuir isotherm model, the sorption occurs at the surface of the sorbent in a homogeneous way and the $\mathrm{CrO}_{4}{ }^{2-}$ ions form a monolayer, having no mutual interactions on the sorbent surface.

Table 3. Isotherm constants for $\mathrm{CrO}_{4}{ }^{2-}$ sorption on the quaternized cellulose

\begin{tabular}{|c|c|c|c|c|c|}
\hline \multicolumn{2}{|c|}{ Langmuir Isotherm Constants } & \multicolumn{3}{c|}{ Freundlich Isotherm Constants } \\
\hline $\begin{array}{c}\mathrm{Q}_{0} \\
\left(\mathrm{mg} \cdot \mathrm{g}^{-1}\right)\end{array}$ & $\mathrm{b}(\mathrm{L} / \mathrm{mg})$ & $\mathrm{R}^{2}$ & $\mathrm{~K}_{\mathrm{F}}(\mathrm{mg} / \mathrm{g})$ & $\mathrm{n}$ & $\mathrm{R}^{2}$ \\
\hline 3.91 & 0.13 & 0.9997 & 2.09 & 9.23 & 0.9575 \\
\hline
\end{tabular}

The theoretical capacity of the prepared sorbent is compared with others reported in literature and results are summed up in Table 4.
Table 4. Comparison of the sorption capacity of biomass and other biomaterials

\begin{tabular}{|l|c|c|}
\hline Sorbent & $\begin{array}{c}\text { Capacity } \\
\text { (mg/g) }\end{array}$ & Reference \\
\hline $\begin{array}{l}\text { Succinylated mercerized cellulose functionalized } \\
\text { with quaternary ammonium groups }\end{array}$ & 96.16 & {$[31]$} \\
\hline Chitosan & 7.94 & {$[32]$} \\
\hline Iron (III) hydroxide-loaded sugar beet pulp & 5.12 & {$[33]$} \\
\hline Cellulose-Clay Composite Biosorbent & 22.20 & {$[34]$} \\
\hline Polyethylenimine Facilitated Ethyl Cellulose & 36.80 & {$[35]$} \\
\hline Amine-crosslinked cotton stalk peel & 129.0 & {$[2]$} \\
\hline Coconut tree sawdust functionalized & 3.46 & {$[36]$} \\
\hline $\begin{array}{l}\text { Quaternary ammonium groups fund } \\
\text { cellulose }\end{array}$ & 3.91 & This work \\
\hline
\end{tabular}

The capacity of prepared sorbents varies from 3.46 to $129 \mathrm{mg} / \mathrm{g}$. The modification way, its duration and modification materials strongly affect sorption capacity.

\subsection{Thermodynamic parameters}

To analyze the effect of temperature on the sorption of sorption $\mathrm{CrO}_{4}{ }^{2-}$ onto ion-exchange cellulose, experiments were conducted at different temperatures and thermodynamic parameters were calculated from the Van't Hoff's plot. Changes in standard free energy $\left(\Delta \mathrm{G}^{\circ}\right)$, entropy $\left(\Delta \mathrm{S}^{\circ}\right)$ and enthalpy $\left(\Delta \mathrm{H}^{\circ}\right)$ were estimated by the following Eq. 6-8 [37,38]

$$
\begin{array}{r}
\Delta G^{0}=-\mathrm{RT} \ln K_{c}^{0} . \\
\ln K_{c}^{0}=\frac{\Delta \mathrm{S}^{0}}{\mathrm{R}}-\frac{\Delta \mathrm{H}^{0}}{\mathrm{RT}} \ldots \ldots \ldots \ldots \\
\Delta G^{\circ}=\Delta H^{\circ}-T \Delta S^{\circ} \ldots \ldots \ldots
\end{array}
$$

In these equations, $\mathrm{K}_{\mathrm{c}}$ is the equilibrium constant and it was calculated by $\mathrm{q}_{\mathrm{e}} / \mathrm{C}_{\mathrm{e}}, \mathrm{R}$ is the universal gas constant $\left(8.314 \mathrm{~J} \mathrm{~mol}^{-1} \mathrm{~K}^{-1}\right)$, and $\mathrm{T}$ is the temperature $(\mathrm{K})$. Parameters change in enthalpy $\left(\Delta \mathrm{H}^{0}\right)$ and change in entropy $\left(\Delta \mathrm{S}^{0}\right)$ are calculated from the slope and the intercept of the linear plot of $\ln \mathrm{K}_{\mathrm{c}}$ Vs. $1 / \mathrm{T}$. The calculated values are summarized in Table 5 .

Table 5. Thermodynamic parameters for $\mathrm{CrO}_{4}{ }^{2-}$ sorption

\begin{tabular}{|c|c|c|}
\hline $\boldsymbol{\Delta} \mathbf{S}^{\mathbf{0}} / \mathbf{J} \mathbf{~ m o l}^{\mathbf{- 1}} \mathbf{K}^{-\mathbf{1}}$ & $\boldsymbol{\Delta} \mathbf{H}^{\mathbf{0}} / \mathbf{k J} \mathbf{~ m o l}^{\mathbf{1}}$ & $\boldsymbol{\Delta} \mathbf{G}^{\mathbf{0}} / \mathbf{k J} \mathbf{~ m o l}^{-\mathbf{1}}$ \\
\hline & & $-7.08 / 313 \mathrm{~K}$ \\
4.62 & -5.63 & $-7.13 / 323 \mathrm{~K}$ \\
& & $-7.17 / 333 \mathrm{~K}$ \\
\hline
\end{tabular}

The negative values of $\Delta G^{\circ}$ at all temperatures studied are due to the fact that the ion-exchange reaction is spontaneous. The negative value of $\Delta H^{\circ}$ suggests the exothermic nature of the ion-exchange reaction. The positive value of $\Delta S^{\circ}$ suggests increased randomness at the quaternized cellulose/solution interface during the sorption of $\mathrm{CrO}_{4}^{2-}$ onto the cellulose.

\subsection{Regeneration of the sorbent}

1.0 grams of quaternized cellulose was contacted $50 \mathrm{ml}$ of $\mathrm{CrO}_{4}{ }^{2-}$ solution (500 mg- $\mathrm{CrO}_{4}{ }^{2-} / \mathrm{L}$ ) for one hour. Later, the sorbent was separated from the solution by decantation and washed with deionized water then dried in an oven at $40{ }^{\circ} \mathrm{C}$. The $\mathrm{CrO}_{4}{ }^{2-}$ concentration in feed and effluent was analyzed and loaded amount of $\mathrm{CrO}_{4}{ }^{2-}$ on quaternized cellulose was calculated. An $0.025 \mathrm{~g}$ of dry $\mathrm{CrO}_{4}{ }^{2-}$-loaded sorbent was contacted with $25 \mathrm{~mL}$ regeneration solutions, then the mixture was shaken at room temperature for 24 hours and after this period $\mathrm{CrO}_{4}{ }^{2-}$ concentration in the solution was determined. Regeneration efficiency (RE,\%) was calculated using the Equation Eq. (9) and the obtained results were summarized in Table 6.

$$
\mathrm{RE}(\%)=\frac{\text { Amount of eluated } \mathrm{CrO}_{4}{ }^{2-}}{\text { Amount of loaded } \mathrm{CrO}_{4}{ }^{2-}} \times 100
$$


Table 6. Percentage recovery of $\mathrm{CrO}_{4}{ }^{2-}$ by different regeneration solution

\begin{tabular}{|c|c|}
\hline Regenerated by & Regeneration efficiency \\
\hline $0.1 \mathrm{M} \mathrm{HCl}$ & 85 \\
\hline $0.5 \mathrm{M} \mathrm{HCl}$ & 88 \\
\hline $1.0 \mathrm{M} \mathrm{HCl}$ & 95 \\
\hline
\end{tabular}

As can be seen from Table 6, when the $\mathrm{HCl}$ concentration was increased the regeneration efficiency increased. $1.0 \mathrm{M} \mathrm{HCl}$ solution can regenerate the $\mathrm{CrO}_{4}{ }^{2-}$ -loaded cellulose with $95 \%$ efficiency.

\section{CONCLUSIONS}

The anion exchange cellulose was synthesized and applied for the removal of $\mathrm{CrO}_{4}{ }^{2-}$ ions from aqueous solutions. The removal of $\mathrm{CrO}_{4}{ }^{2-}$ ions from aqueous solution by prepared cellulose was found to be effective with $99 \%$ removal efficiency. The kinetic of $\mathrm{CrO}_{4}{ }^{2-}$ removal is quite fast and in 5 minutes it reached equilibrium. Removal of $\mathrm{CrO}_{4}{ }^{2-}$ is $\mathrm{pH}$ depended and removal rate increased with increment on initial solution $\mathrm{pH}$. Optimum $\mathrm{pH}$ for $\mathrm{CrO}_{4}{ }^{2-}$ removal was found to be $\geq 6$. Equilibrium data fitted to the Langmuir model very well which means that $\mathrm{CrO}_{4}{ }^{2-}$ might be sorbed in the formation of a monolayer coverage on the surface of anion-exchange cellulose. The $\mathrm{CrO}_{4}{ }^{2-}$ loaded cellulose can be regenerated with $1.0 \mathrm{M} \mathrm{HCl}$ solution.

\section{ACKNOWLEDGMENT}

This study is supported by Ege University Scientific Research Projects Coordination Unit (Project Number: 18-FEN-044). The author thanks Denkim Kimya A.Ş. for proving the cellulose samples.

\section{REFERENCES}

1. Z. Rawajfih and N. Nsour, J. Chem. Thermodyn. 40, 846 (2008).

2. X. Xu, B.-Y. Gao, X. Tang, Q.-Y. Yue, Q.-Q. Zhong, and Q. Li, J. Hazard. Mater. 189, 420 (2011).

3. L. K. Cabatingan, R. C. Agapay, J. L. L. Rakels, M. Ottens, and L. A. M. van der Wielen, Ind. Eng. Chem. Res. 40, 2302 (2001).

4. T. Hajeeth, P. N. Sudha, K. Vijayalakshmi, and T. Gomathi, Int. J. Biol. Macromol. 66, 295 (2014).

5. S. Kuo and R. Bembenek, Bioresour. Technol. 99, 5617 (2008).

6. J. Sánchez, N. Mendoza, B. L. Rivas, L. Basáez, and J. L. Santiago-García, J. Appl. Polym. Sci. 134, 45355 (2017).

7. R. A. Anderson, Sci. Total Environ. 86, 75 (1989).

8. J. Kotaś and Z. Stasicka, Environ. Pollut. 107, 263 (2000).

9. W. H. Organization, Guidelines for Drinking-Water Quality (2004).

10. J. Sánchez, B. Butter, L. Basáez, B. L. Rivas, and M. O. Thotiyl, J. Chil. Chem. Soc. 62, 3647 (2017).

11. Y. S. Dzyazko, L. M. Rozhdestvenskaya, S. L. Vasilyuk, V. N. Belyakov, N. Kabay, M. Yuksel, O. Arar, and U. Yuksel, Chem. Eng. Commun. 196, 3 (2008).

12. Y. S. Dzyazko, S. L. Vasilyuk, L. M. Rozhdestvenskaya, V. N. Belyakov, N. V. Stefanyak, N. Kabay, M. Yüksel, Ö. Arar, and Ü. Yüksel, Chem. Eng. Commun. 196, 22 (2008).

13. F. Gode and E. Pehlivan, J. Hazard. Mater. 119, 175 (2005).

14. N. Hamadi, Chem. Eng. J. 84, 95 (2001).

15. U. Farooq, J. A. Kozinski, M. A. Khan, and M. Athar, Bioresour. Technol. 101, 5043 (2010)

16. A. Asthana, R. Verma, A. K. Singh, and M. A. B. H. Susan, J. Environ. Chem. Eng. 4, 1985 (2016).

17. W. Jiang, W. Wang, B. Pan, Q. Zhang, W. Zhang, and L. Lv, ACS Appl. Mater. Interfaces 6, 3421 (2014).

18. P. Kanmani, J. Aravind, M. Kamaraj, P. Sureshbabu, and S. Karthikeyan, Bioresour. Technol. 242, 295, (2017).

19. D. Roy, M. Semsarilar, J. T. Guthrie, and S. Perrier, Chem. Soc. Rev. 38, 2046 (2009).

20. C. Miao and W. Y. Hamad, Cellulose, 20, 2121 (2013).

21. H. Kargarzadeh, M. Mariano, D. Gopakumar, I. Ahmad, S. Thomas, A. Dufresne, J. Huang, and N. Lin, Cellulose, 25, 2151 (2018).

22. R. J. Moon, A. Martini, J. Nairn, J. Simonsen, and J. Youngblood, Chem. Soc. Rev. 40, 3941 (2011).

23. A. Pei, N. Butchosa, L. A. Berglund, and Q. Zhou, Soft Matter 9, 2047 (2013).
24. A. . Clesceri, L., Greenberg, A. \& Eaton, Standard Methods for the Examination of Water and Wastewater (1999).

25. P. Larkin, Infrared and Raman spectroscopy: principles and spectral interpretation Elsevier, San Diego, 2011.

26. R. G. Zhbankov, Infrared spectra of cellulose and its derivatives; Springer, New York, 1995.

27. E. Parlak and Ö. Arar, J. Dispers. Sci. Technol. 39, 1403 (2018).

28. G. Ozkula, B. F. Urbano, B. L. Rivas, N. Kabay, and M. Bryjak, J. Chil. Chem. Soc. 61, 2752 (2016).

29. B. Alyüz and S. Veli, J. Hazard. Mater. 167, 482 (2009).

30. P. Liu, Y. Li, Y. Xu, Y. Qing, and C. Han, J. Chil. Chem. Soc. 63, 3819 (2018).

31. L. V. A. Gurgel, J. C. Perin de Melo, J. C. de Lena, and L. F. Gil, Bioresour. Technol. 100, 3214 (2009).

32. Y. A. Aydin and N. D. Aksoy, Chem. Eng. J. 151, 188 (2009).

33. H. S. Altundogan, Process Biochem. 40, 1443 (2005).

34. A. S. K. Kumar, S. Kalidhasan, V. Rajesh, and N. Rajesh, Ind. Eng. Chem. Res. 51, 58 (2012).

35. B. Qiu, C. Xu, D. Sun, H. Yi, J. Guo, X. Zhang, H. Qu, M. Guerrero, X. Wang, N. Noel, Z. Luo, Z. Guo, and S. Wei, ACS Sustain. Chem. Eng. 2, 2070 (2014).

36. K. Selvi, Bioresour. Technol. 80, 87 (2001).

37. D. V. Morales, B. L. Rivas, and M. González, J. Chil. Chem. Soc. 61, 3295 (2016).

38. M. Duran, Ö. Arar, and M. Arda, J. Chil. Chem. Soc. 64, 4399 (2019). 